\section{The American Association for Thoracic Surgery}

\section{AATS International Thoracic Surgical Oncology Summit}

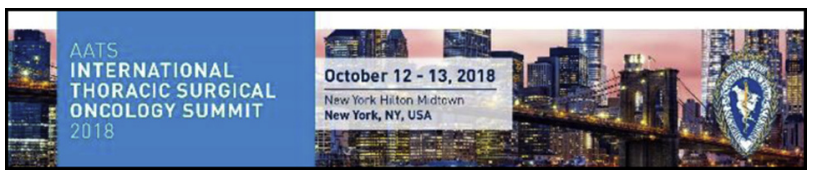

\section{Preliminary Program Now Available}

October 12-13, 2018

New York Hilton Midtown

New York, NY

Program Directors: David R. Jones and David J. Sugarbaker

The AATS International Thoracic Surgical Oncology Summit is a cannot-miss educational opportunity for everyone involved in the rapidly changing field of thoracic surgical oncology. The unparalleled content focuses on new technologies to stage and treat cancers of the lung, esophagus, mediastinum, and pleura, as well as the latest biological and immunologic therapies used along with surgery to improve survival and quality of life of patients. Surgeons and oncologists will learn about novel approaches and how to use them in their practices through a variety of interactive and informative presentations including peer-reviewed abstracts, dynamic debates, and "How I Do It" videos from recognized experts.

Newly added to the program-Breakfast of Champions: Finding Your First Job Breakfast Session will take place Saturday morning. Moderated by Daniela Molena, Memorial Sloan Kettering Cancer Center and Scott J. Swanson, Brigham and Women's Hospital

For more information, visit www.aats.org/thoracicsummit

\section{AATS Week}

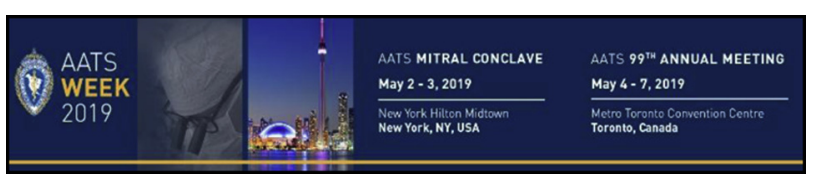

Call for Abstracts and Videos

\section{AATS Mitral Conclave}

May 2-3, 2019

New York Hilton Midtown

New York, NY, USA

Program Director:

David H. Adams
AATS 99th Annual Meeting

May 4-7, 2019

Metro Toronto Convention Centre

Toronto, Canada

President: David H. Adams

The abstract and video submission sites are now open for the AATS Week events: the 2019 AATS Mitral Conclave and AATS 99th Annual Meeting.

AATS Mitral Conclave, May 2-3, 2019, in New York, NY Submission Deadline: Sunday, January 6, 2019, at 11:59 PM EST

AATS 99th Annual Meeting, May 4-7, 2019, in Toronto, Canada

Submission Deadline: Tuesday, October 30, 2018, at 11:59 PM EST

The 99th AATS Annual Meeting format has been redesigned to enhance the educational opportunities for all attendees. From the opening Plenary Session, on Saturday, May 4th, to the last of the over 75 simultaneous breakout and video sessions on Tuesday, May 7th, the meeting will have a completely different feel than previous years, allowing customization of your scholarship experience like never before.

For additional information regarding submission categories and deadlines, please visit the AATS Web site.

\section{AATS Focus on Thoracic Surgery: Lung and Esophageal Cancer}

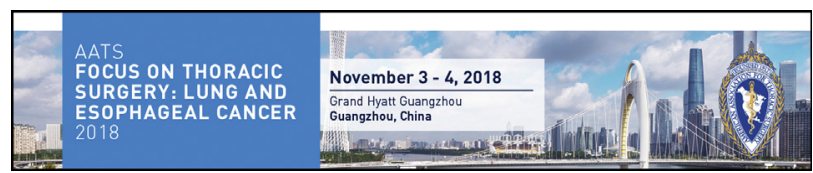

November 3-4, 2018

Grand Hyatt Guangzhou

Guangzhou, China

Program Directors

Jianxing $\mathrm{He}$

G. Alexander Patterson

David J. Sugarbaker

\section{Program Overview}

Lung cancer and esophageal cancer remain a global concern for patients and thoracic surgeons as two of the deadliest malignancies worldwide. The 2018 AATS Focus on Thoracic Surgery: Lung and Esophageal Cancer meeting will concentrate on the complex issues involved with treating both 